\title{
Docetaxel and cisplatin in patients with advanced gastric cancer: results of Japanese phase I/II study
}

\author{
SOH SAITOH ${ }^{1}$ and YuH SAKATA ${ }^{2}$ \\ ${ }^{1}$ Aomori Prefectural Central Hospital, 2-1-1 Higashi-tsukurimichi, Aomori 030-8553, Japan \\ ${ }^{2}$ Misawa Municipal Hospital, Misawa, Japan
}

\begin{abstract}
Two phase II monotherapy studies of docetaxel in patients with advanced gastric cancer were performed in Japan. In group A, docetaxel showed an overall response rate of $23.7 \%$ $(14 / 59)$ in 59 patients, and the adverse reactions were tolerable. In group $B$, this agent showed the same response rate, of $23.7 \%(14 / 59)$ and the same adverse reaction profile.

We then conducted the phase I/II studies of docetaxel and cisplatin for advanced gastric cancer. A Japanese phase I study in patients with advanced gastric cancer established that docetaxel $60 \mathrm{mg} / \mathrm{m}^{2}$ could be given together with cisplatin $80 \mathrm{mg} / \mathrm{m}^{2}$ without any dose-limiting toxicity. In a phase II trial of this combination regimen in 25 evaluable patients with advanced or recurrent disease, the overall response rate was $28 \%(7 / 25)$, and the response rate for liver metastases was $40 \%(6 / 15)$. Hematological and nonhematological toxicities were acceptable. It is concluded that this regimen is feasible and might warrant further investigation in respect to its relatively high response rate for liver metastases.
\end{abstract}

Key word Docetaxel $\cdot$ Cisplatin $\cdot$ Gastric cancer

\section{Introduction}

Gastric cancer remains one of the leading causes of death due to malignant neoplasms in Japan, even though its incidence is decreasing. Gastric cancer was long considered to respond poorly to chemotherapy. However, relatively high response rates have recently been reported for newly developed drugs and combination regimens. Nevertheless, the median survival has been less than 1 year. There remains a need for new effective and well-tolerated regimens.

Offprint requests to: S. Saitoh

Received: November 5, 2002 / Accepted: November 11, 2002
Cisplatin is frequently used in Japan for the treatment of advanced gastric cancer [1-3]. Docetaxel has recently shown impressive activity against this disease, with a single-agent response rate (RR) of between $17 \%$ and $24 \%$ and a median survival of 6.2 to 7.9 months [4-7]. In Europe and the United States, combination regimens with docetaxel in the treatment of gastric cancer have also produced promising results [8-10]. In Japan, a phase I study used cisplatin and docetaxel in combination, with the aim of determining the maximum tolerated doses (MTDs) of the two agents, the clinical toxicities of their administration, and preliminary evidence of activity [11]. This was followed by a larger phase II trial, the results of which are reported here, after a brief account of two independent phase II monotherapy studies that assessed the activity of this drug in Japan.

\section{Docetaxel phase II monotherapy studies}

\section{Docetaxel phase II monotherapy study (group A)}

A late phase II clinical study of docetaxel was conducted in patients with advanced or recurrent gastric cancer as a multicenter cooperative trial. Docetaxel was administered intravenously at a dose of $60 \mathrm{mg} / \mathrm{m}^{2}$ every 3-4 weeks. From January 1994 to August 1997, 76 patients were enrolled in this study. Of the 76 patients entered, 66 patients were eligible and 59 patients were evaluable for the response. One patient showed a complete response (CR); 13 patients, a partial response (PR); 1 patient, a minor response (MR); 19 patients showed no change (NC); and 25 patients had progressive disease (PD). The overall response rate in the 59 evaluable patients was $23.7 \%$ (95\% confidence interval [CI], 13.6\%-36.6\%). The primary tumors showed a $4.3 \%(1 / 23)$ response rate, while the metastatic lesions in the abdomen, pelvic mass, lung, liver, and lymph 
nodes showed response rates of $62.5 \%(5 / 8), 33.3 \%(1 /$ 3), $33.3 \%(1 / 3), 14.8 \%(4 / 27)$, and $19.3 \%$ (5/26), respectively. As hematological toxicities, severe (grade 3 or higher) leukopenia was observed in 36 of 64 patients $(56.3 \%)$ and neutropenia was observed in 52 of 64 patients $(81.3 \%)$. Other major toxicities (grade 3 or higher) included nausea/vomiting in 11 of 64 patients $(17.2 \%)$, anorexia in 9 of 64 patients $(14.1 \%)$, fatigue in 5 of 64 patients $(7.8 \%)$, and alopecia in 7 of 64 patients $(10.9 \%)$, all of which toxicities were tolerable.

These results indicate that docetaxel is an effective anticancer agent for advanced/recurrent gastric cancer [6].

\section{Docetaxel phase II monotherapy study (group B)}

In accordance with a request from the Ministry of Health and Welfare, another late phase II clinical study of docetaxel in patients with advanced or recurrent gastric cancer was performed independently during the same period as a multicenter cooperative trial to evaluate the antitumor activity and clinical toxicity. Docetaxel was administered intravenously at a dose of $60 \mathrm{mg} / \mathrm{m}^{2}$ every 3-4 weeks. From January 1994 to February 1998, 72 patients were enrolled in this study. Sixtythree patients were eligible, and 59 patients were evaluable for the response. Evaluation of the antitumor effects showed CR in 1 patient, $\mathrm{PR}$ in 13, MR in 3, NC in 20 , and PD in 22 patients. The overall response rate was $23.7 \%(14 / 59)$. In the $14 \mathrm{CR}$ and PR patients, the response appeared after 10 to 107 days (median, 33.5 days) or one to eight (median, 2) treatment courses following the initial administration. The response rate was $9.5 \%$ for the primary tumors, $31.3 \%$ for liver metastases, $50.0 \%$ for abdominal tumors, and $24.1 \%$ for lymph node metastases. The major adverse reactions were gastrointestinal symptoms, including nausea/vomiting, anorexia, fatigue, alopecia, and fever. Leukocytopenia and neutropenia were also observed at high incidences, but they resolved within 8 days following the nadir.

These results indicate that docetaxel is an effective antitumor agent for advanced or recurrent gastric cancer. It was considered necessary to conduct another clinical trial by concomitant administration with other antitumor agents [7].

\section{Docetaxel plus cisplatin: phase I/II study}

Two recent studies have reported high response rates, of between $37.2 \%$ and $56 \%$, with the combination of docetaxel and cisplatin in advanced or recurrent gastric cancer in Europe [8,9]. A phase I/II study was conducted to investigate the tolerability and the efficacy of this combination in Japanese patients. The phase I study was designed to determine the recommended dose of cisplatin in combination with $60 \mathrm{mg} / \mathrm{m}^{2}$ of docetaxel. The phase II study was performed to evaluate the antitumor activity and the tolerability of this combination when administered at the recommended doses determined in the phase I study.

\section{Phase I study}

In this dose-escalation trial, docetaxel was administered at a fixed dose of $60 \mathrm{mg} / \mathrm{m}^{2}$, and cisplatin at $60 \mathrm{mg} / \mathrm{m}^{2}$ at dose level 1. The cisplatin dose was then escalated, in increments of $10 \mathrm{mg} / \mathrm{m}^{2}$, to a maximum of $80 \mathrm{mg} / \mathrm{m}^{2}$ at dose level 3. This dose escalation schedule was based on earlier Japanese experience with this combination for the treatment of non-small cell lung cancer patients [11]. In the phase I trial of lung cancer, the recommended doses of this combination were decided to be docetaxel $60 \mathrm{mg} / \mathrm{m}^{2}$ and cisplatin $80 \mathrm{mg} / \mathrm{m}^{2}$, with no dose-limiting toxicity (DLT).

In the present trial, three patients were entered at each of three dose levels, and a total of 32 courses of this combination chemotherapy were administered. All patients were assessable for toxicity. DLT was defined as the occurrence, during the first cycle, of grade 4 leukopenia or neutropenia lasting for more than 5 days, febrile neutropenia (grade 4 neutropenia with a body temperature of $38^{\circ} \mathrm{C}$ or more), grade 4 thrombocytopenia, greater than grade 2 renal toxicity, or greater than grade 3 hepatic or other toxicities, except for nausea/ vomiting, anorexia, diarrhea, abdominal pain, and fatigue. By these criteria, no DLT was observed during the dose-escalation study, and the combination of docetaxel $60 \mathrm{mg} / \mathrm{m}^{2}$ and cisplatin $80 \mathrm{mg} / \mathrm{m}^{2}$ was recommended for use in the phase II study. In this phase I trial, one patient achieved a PR at dose level 2 (docetaxel $60 \mathrm{mg} / \mathrm{m}^{2}$ and cisplatin $70 \mathrm{mg} / \mathrm{m}^{2}$ ).

\section{Phase II study}

This phase II trial was designed to evaluate the efficacy of the combination chemotherapy of docetaxel and cisplatin against advanced or recurrent gastric cancer, and to evaluate the toxicity of this combination. $\mathrm{Pa}-$ tients eligible for the study had histologically or cytologically confirmed gastric cancer with a measurable or assessable lesion and no prior chemotherapy. Patients were 20 to 74 years old, had a performance status of $0-2$, normal organ function, and a life expectancy of at least 3 months.

Docetaxel was administered at a dose of $60 \mathrm{mg} / \mathrm{m}^{2}$, given as an intravenous infusion over a 1 -h period. After completion of the docetaxel infusion, 3-h prehydration was carried out before the cisplatin infusion. 
Table 1. Patient characteristics of the phase II trial of docetaxel plus cisplatin for advanced or recurrent gastric cancer

\begin{tabular}{lc}
\hline & Number of patients \\
\hline Median age (range) & 59 years $(47-70$ years) \\
Male/female & $23 / 2$ \\
Histological subtype: & 9 \\
$\quad$ Tubular adenocarcinoma & 11 \\
Poorly differentiated & \\
$\quad$ adenocarcinoma & 1 \\
Signet-ring cell carcinoma & 1 \\
$\quad$ Undifferentiated & 3 \\
$\quad$ Others & \\
Stage of disease: & 1 \\
III & 16 \\
IV & 8 \\
Relapse & \\
Performance status: & 21 \\
0 & 3 \\
1 & 1 \\
2 & 17 \\
Site of disease & \\
Primary & 4 \\
Liver & 21 \\
Lung & \\
Lymph node & \\
\hline
\end{tabular}

Cisplatin was infused over a 2-h period, followed by posthydration.

Of the 27 patients entered, 1 received no treatment, and insufficient observation was performed in a second patient. The median age of the 25 patients evaluable for efficacy and toxicity was 59 years (range, 47 to 70 years). The male/female ratio was 23:2. As for the histological subtype, 9 patients had tubular adenocarcinoma and 11 had poorly differentiated adenocarcinoma, with 5 patients showing other histological types (Table 1). One patient had stage 3 disease, 16 had stage 4 disease, and 8 had recurrent disease. The performance status was 0 in 21 patients, 1 in 3 patients, and 2 in 1 patient.

The interim results showed an overall response rate of $28 \%$. Although no CR was observed, there were seven PRs. The response rates by each target site were as follows: $20.0 \%(3 / 15)$ for the primary lesion, $40 \%(6 /$ $15)$ for liver metastases, $25 \%$ (1/4) for lung metastases, and $23.5 \%$ (4/17) for abdominal lymph node metastases. Grade 3 to 4 leukopenia occurred in $76 \%$ of the patients, and neutropenia in $84 \%$. The rates of occurrence of other grade $3 / 4$ toxicities were as follows: nausea and vomiting in $4 \%$ of patients, anorexia in $20 \%$, diarrhea in $20 \%$, fatigue in $12 \%$, and rash in $8 \%$.

\section{Discussion}

Two phase II studies in Japan have assessed docetaxel monotherapy in advanced gastric cancer patients.
Docetaxel at a dose of $60 \mathrm{mg} / \mathrm{m}^{2}$ achieved an overall response rate of $23.7 \%$ as a single agent. This response rate is comparable to the rates achieved with conventional drugs for gastric cancer. The primary tumor showed response rates of $4.3 \%(1 / 23)$ in group $\mathrm{A}$ and $9.5 \%(2 / 21)$ in group B. On the other hand, liver metastases showed response rates of $14.8 \%(4 / 27)$ in group $\mathrm{A}$ and $31.3 \%(5 / 16)$ in group B; abdominal tumors showed response rates of $33.3 \%(1 / 3)$ in group A and $50.0 \%(3 / 6)$ in group B; and the lymph nodes showed response rates of $19.3 \%$ (5/26) in group A and $24.1 \%$ (7/ $29)$ in group B. The liver metastases showed the highest combined response rate, of $20.9 \%$ (9/43). Hematologic toxicities emerged as the main side effects, with grade 3 or more neutropenia experienced by $81.3 \%(52 / 64)$ in group A and $90.0 \%(54 / 60)$ in group B. However, these toxicities were tolerable $[8,9]$. These two monotherapy studies showed that docetaxel was active in patients who had previously been treated with other drugs or in whom previous chemotherapy had failed. This suggests that docetaxel shows no cross-resistance with other drugs commonly used to treat advanced gastric cancer.

The combination of docetaxel and cisplatin was assessed in the phase I/II study reported here. In the phase I part, the recommended dose for the phase II trial was decided as docetaxel $60 \mathrm{mg} / \mathrm{m}^{2}$ and cisplatin $80 \mathrm{mg} / \mathrm{m}^{2}$. At this recommended dose level, the overall response rate, was $28 \%(7 / 25)$, and liver metastases showed the highest response rate, of $40 \%(6 / 15)$. As an adverse reaction, grade 3-4 neutropenia occurred in $84 \%$ of the patients, but they recovered safely.

In conclusion, the combination of docetaxel $60 \mathrm{mg} / \mathrm{m}^{2}$ and cisplatin $80 \mathrm{mg} / \mathrm{m}^{2}$ is active in advanced gastric cancer and can be administered with acceptable toxicity. In particular, this regimen showed a high response rate (40\%) for liver metastases, suggesting its value for the treatment of liver metastasis.

Note: A version of this report [12] originally was published in Gastric Cancer 2002;5:160-7.

\section{References}

1. Furue H. Chemotherapy for gastric cancer in Japan. Jpn J Cancer Chemother 1997; 24(Suppl 1):120-5.

2. Shimada Y, Japan Clinical Oncology Group Gastrointestinal Oncology Study Group. Clinical trials for advanced gastrointestinal cancers in Japan. Cancer Chemother Pharmacol 1998; 42(Suppl): S80-4.

3. Sasaki T, Maeda Y, Kobayashi T, Okamoto R, Omuro Y, Takeda $\mathrm{N}$, et al. Standard chemotherapy for gastrointestinal malignancies based on evidence. Jpn J Cancer Chemother 2000;27:166-76.

4. Einzig AI, Neuberg D, Remick SC, Karp DD, O'Dwyer PJ, Stewart JA, et al. Phase II trial of docetaxel (Taxotere) in patients with adenocarcinoma of the upper gastrointestinal tract previously untreated with cytotoxic chemotherapy: the Eastern Cooperative Oncology Group (ECOG) results of protocol E1293. Med Oncol 1996;13:87-93. 
5. Sulkes A, Smyth J, Sessa C, Dirix LY, Vermorken JB, Kaye S, et al. Docetaxel (Taxotere) in advanced gastric cancer: results of a phase II clinical trial. RORTC Early Clinical Trials Group. Br J Cancer 1994;70:380-3.

6. Taguchi T, Sakata Y, Kanamaru R, Kurihara M, Suminaga M, Ota J, et al. Late phase II clinical study of RP56976 (docetaxel) in patients with advanced/recurrent gastric cancer: a Japanese Cooperative Study Group trial (group A). Jpn J Cancer Chemother 1998;25:1915-24.

7. Mai M, Sakata Y, Kanamaru R, Kurihara M, Suminaga M, Ota J, et al. A late phase II clinical study of RP56976 (docetaxel) in patients with advanced or recurrent gastric cancer: a Japanese Cooperative Study Group trial (group B). Jpn J Cancer Chemother 1999;26:487-96.

8. Roth AD, Maibach R, Martinelli G, Fazio N, Aapro MS, Pagani $\mathrm{O}$, et al. Docetaxel (Taxotere)-cisplatin(TC): an effective drug combination in gastric carcinoma. Ann Oncol 2000;11:301-6.
9. Ridwelski K, Gebauer T, Fahlke J, Kröning H, Kettner E, Meyer $\mathrm{F}$, et al. Combination chemotherapy with docetaxel and cisplatin for locally advanced and metastatic gastric cancer. Ann Oncol 2001;12:47-51.

10. Kettner E, Ridwelski K, Keilholz U, Gullkowski U, Gebauer T, Kröning $\mathrm{H}$, et al. Docetaxel and cisplatin combination chemotherapy for advanced gastric cancer: results of two phase II studies (abstract). Proc Am Soc Clin Oncol 2001;20:657.

11. Watanabe K, Hayashi I, Segawa Y, Hiraki S, Niitani H. Phase I/II study of docetaxel and cisplatin in patients with previously untreated metastatic non-small cell lung cancer (abstract). Ann Oncol 1998;9:91(Suppl 4):437.

12. Mitachi Y, Sakata Y, Ohtsu A, Hyodo I, Katsu K, Sairenji M, et al. Docetaxel and cisplatin in patients with advanced or recurrent gastric cancer: a multicenter phase I/II study. Gastric Cancer 2002;5:160-7. 